\title{
ROLE VARIATIONS OF PERFORMANCE MEASUREMENT IN DUTCH LOCAL GOVERNMENT
}

\author{
Willem Jan van Elsacker
}

Faculty of Economics and Business, University of Groningen, The Netherlands Henk J. ter Bogt

Faculty of Economics and Business, University of Groningen, The Netherlands and

\section{G. Jan van Helden}

Faculty of Economics and Business, University of Groningen, The Netherlands

\begin{abstract}
This paper examines differences in roles of performance measurement in Dutch local government under diverging contexts - businesslike and political - and varying degrees of standardisation of activities. The research shows that some of these roles apply irrespective of the values of both contingency variables. This holds for the so-called standard roles of diagnostic control, influencing future budgets and reporting. However, other roles of performance measurement, especially signalling and learning, only emerge related to specific contextual circumstances. If a policy field is, for instance, highly politically sensitive, these additional roles are important, and can even lead to tight controls. In these circumstances the standard roles also become more pronounced.
\end{abstract}

\section{INTRODUCTION}

During the last two decades New Public Management (NPM) has been an important international trend in the public sector (Hood, 1995). NPM also substantially influenced the public sector in the Netherlands. Two major changes are generally associated with this influence. The first is a change in the organisational structure of public sector organisations, i.e. from centralisation to decentralisation and autonomy of organisational units. The second change refers to the introduction of businesslike planning and control instruments, such as medium-term plans, output budgets, hierarchical planning and control systems, and performance 
van Elsacker, ter Bogt \& van Helden

reports (van Helden and Johnsen, 2002, p. 77; ter Bogt and van Helden, 2005, pp. 255-260).

At the core of the second change especially is performance measurement $(\mathrm{PM})$, which can be used for both external-oriented communication and for internal-oriented strategic, political and operational reasons (ter Bogt, 2003, 2004). Many Dutch local government organisations currently have adopted financial and non-financial performance indicators for accounting and control purposes (Bordewijk and Klaassen, 2000; van Helden and ter Bogt, 2001; van Helden and Johnsen, 2002, p. 77). Although the adoption of performance measurement systems seems to be inevitable in almost all Western countries, there is still a huge debate on both their content and the conditions under which those systems are successful or at least appreciated by relevant stakeholders (de Bruijn, 2002, chapter 2; Behn, 2003).

This also holds for Dutch local government. Unlike the widespread adoption of performance measurement systems in Dutch municipalities, research findings point to a limited use of these systems. Various reasons for this arise from research. First, the relevance of PM information for decision making and control is questioned, because performance indicators mainly refer to numbers of service units, whereas cost per unit and quality indicators are scarce (van Helden and Johnsen, 2002, p. 88). Second, municipal performance indicators are often decoupled from budgets, which also implies that PM information is hardly used for budget allocation purposes (Bordewijk and Klaassen, 2000). Third, municipal politicians do not intensively use PM information for planning and control and for evaluation of their top managers, because they seem to prefer 'rich', verbal and informal information (ter Bogt, 2003, 2004).

The research indicated above emphasises a tension between, on the one hand, a widespread adoption of PM information, and, on the other hand, a limited 'rational' use for formal organisational control (see Anthony, 1988, p. 133-134). This raises the following question: if PM is not primarily used in a rational way for organisational control, for what reasons is PM then applied? Or, to put it differently, which roles can PM play under varying circumstances in governmental organisations in general and in Dutch municipalities in particular? This study concentrates on this last question, and aims to explain the roles of PM in Dutch local government.

The paper is structured as follows. The next section develops a theoretical framework for understanding different roles of PM. Then, the research design is discussed. The fourth section presents the case research findings. After this, a redesign of the theoretical framework is discussed. The final section presents some reflections and conclusions.

\section{LITERATURE REVIEW AND THEORETICAL FRAMEWORK}

The introduction of businesslike planning and control and performance measurement can be regarded as a change in the management control of local government. In this paper, management control includes 'all the devices managers use to 
ensure that the behaviour and decisions of people in the organization are consistent with the organization's objectives and strategies' (Merchant and Van der Stede, 2003, p. 4). These devices can in practice involve many kinds of control mechanisms, which can be formal or informal in nature. Such a broad definition of management control could also be denoted as organisational control (see, for example, Birnberg, Turopolec and Young, 1983, p. 117; Birnberg, 1998, pp. 37-39; see also Chenhall, 2003, p. 129).

During the last decades various authors have discussed management control and the role that accounting and performance information in different situations could have to control organisations. An accounting information system (AIS) is a system that can support management control; it refers to formal routines and procedures, the use of information and a focus on patterns of activities. Taking an orthodox management accounting perspective, the function of the AIS is to facilitate decision making and to control behaviour (Zimmerman, 2000, p. 3). Research in the field of contingency theory has focused, for example, on factors that could explain the design and role of the AIS. That is, the AIS has to 'fit' one or more contingency variables, for example size, task uncertainty or strategy (Chenhall, 2003, pp. 160-161). Donaldson (2001, pp. 215, 218-226) suggests that there is 'overwhelming evidence' that fit indeed affects organisational performance.

This section presents the ideas about management control and the role of accounting and performance information of some 'classical' authors, such as Ouchi, Hofstede, and Earl and Hopwood, and links them to ideas presented more recently by authors like Simons, Chapman, and Merchant and Van der Stede. Then, based on this literature review, a theoretical framework will be developed.

\section{Performance Measurement and Control}

Ouchi (1979, p. 833) analyses three fundamentally different mechanisms to evaluate and control organisations. The applicability of these control forms, i.e. markets, bureaucracies and clans, depends on the measurability of organisational outputs and the knowledge of the transformation process, i.e. the programmability of tasks (Perrow, 1970). In Ouchi's (1979) control model, behaviour controls can be applied when the knowledge of the transformation process is high. Organisations may use output or results controls when the measurability of the outputs is high. When the knowledge of the transformation process and the measurability of outputs are low, i.e. the possibility to assess performance is unclear, an organisation is likely to use more informal, social, ritualised or ceremonial forms of control. However, Ouchi $(1979$, p. 840) adds, organisations in practice will contain some features of each of the control forms.

Implicit in Ouchi's (1979) analysis is the assumption that organisational control operates whilst agreement on goals and objectives exists (Birnberg et al., 1983 , p. 115). It is, however, doubtful whether this assumption of unambiguous 
van Elsacker, ter Bogt \& van Helden

objectives is always valid. Hofstede (1981, p. 194) argues that unambiguity of objectives is 'the most crucial criterion for management control'. He states:

\begin{abstract}
When ambiguities in objectives exist, control is always political control, dependent on power structures, negotiation processes, the need for the distribution of scarce resources, particular interests and conflicting values: however, political control at the top of an organization can go together with other forms of control inside the organization, because, for members, the political top may have resolved the ambiguities (Hofstede, 1981, p. 198).
\end{abstract}

Apart from ambiguity of objectives, Hofstede (1981) uses three other criteria in his framework, i.e. measurability of outputs, knowledge of the effects of management interventions and the level of repetitiveness of activities. In principle, when objectives are unambiguous and outputs are measurable, cybernetic control models can be applied (i.e. it is possible to calculate variances between actual performance and pre-set norms to decide whether intervention in the task execution or adjustment of norms is appropriate). Control models will become less cybernetic when goals are ambiguous, or when effects of interventions are not known. Non-cybernetic control may rely more on the values and rituals, i.e. the culture, of the group in which decision-makers operate (see also Macintosh, 1994, pp. 128-141). No universally optimal procedures for noncybernetic control exist. Political control is, as Hofstede (1981, p. 202) puts it, 'a vague model'.

Although its role may vary according to the circumstances, the AIS can be of help to control organisations. Budgeting is a major feature of most AIS. Dutch municipalities use budgets, for instance in their hierarchical planning and control documents, which support various functions, such as planning, information provision, accountability and control (van Helden and ter Bogt, 2001). In the Dutch government sector, performance measures relate primarily to activities, outputs and outcome (ter Bogt, 2004). Nowadays, performance measures are an important part of governmental budgets in the Netherlands (van Helden and Johnsen, 2002, p. 76).

Budgets can contribute considerably to the tightness of formal control systems, but budgetary control is only one way to exercise tight control; personnel and cultural control can also contribute to tight control. Budgetary control is considered to be tighter if it has a greater effect on decision making or if it provides a higher degree of certainty that employees act in a desired way (Merchant and Van der Stede, 2003, pp. 124-131). Control tightness is in general related to diagnostic controls, which are in essence cybernetic controls, using budgets and variance analysis on important targets to focus managers' attention (Simons, 1995, pp. 60-61, 161). Tightness is, however, not exclusively related to diagnostic controls, as research by Van der Stede (2001) shows.

The notion that the role of an AIS in decision making and control can be different in different situations was normatively explored by Earl and Hopwood (1979) and Burchell, Clubb, Hopwood, Hughes and Nahapiet (1980; see also Macintosh, 1994, pp. 150-162; Chenhall, 2003, p. 140). Earl and Hopwood (1979) 
distinguished between two forms of uncertainty, namely uncertainty over objectives (or disagreement on objectives) and uncertainty of cause and effect (that is, the relationship between actions and their consequences, which is similar to the concepts of programmability of tasks or task uncertainty). Earl and Hopwood (1979) and Burchell et al. (1980) argue that when uncertainty on both dimensions is low, decision-making is structured and can be based on computation, and control is assumed to be programmable. The associated role of AIS is labelled as 'answering machine'. In a situation in which uncertainty about objectives is low and uncertainty of cause and effect is high, the AIS cannot provide answers, but it could assist to explore problems, ask questions and analyse the analysable. Earl and Hopwood (1979, p. 8) labelled this as a 'learning machine role'.

Earl and Hopwood (1979) indicate that in a situation of uncertainty or disagreement over objectives and relative certainty on causation (on the relationship between actions and consequences), the AIS can have the role of a 'dialogue machine', in which values, interests, conflicts and bargaining play a main role. In that situation, political processes, which often include discussion, seeking conflict resolution, or just talking, are important. Probably somewhat more 'cynical', Earl and Hopwood (1979) and Burchell et al. (1980) suggest that in reality in this situation the role of accounting information could be that of an 'ammunition machine', through which interested parties seek to promote their particular positions. When causation and objectives are highly uncertain they argue that, with a need for inspiring and creativity-triggering information, the AIS ideally could be used as an 'idea machine'. However, somewhat cynically again, in reality in such a situation the AIS might rather serve as a 'rationalisation machine', the main purpose of which is to legitimise the organisation and its actions towards its external constituencies (Earl and Hopwood, 1979, p. 9; Burchell et al., 1980, p. 15).

With their explicit notion that accounting information can have a different role in different situations and their categorisation of these roles, Earl and Hopwood (1979) offer a partial basis for studying the ways in which performance information is used in Dutch local government. Some later developments in control literature seem to (partly) fit the Earl and Hopwood (1979) model. For example, Chapman (1997, p. 201) also suggests a relationship between accounting roles and uncertainty. Further, it seems that the answering machine role shows a high degree of correspondence with Simons' diagnostic role (see also Simons, 1995, pp. 71-74, 124; Abernethy and Brownell, 1997, p. 191; Chenhall, 2003, p. 133). Probably, this role could specifically be applied in situations in which Hofstede (1981) would suggest a cybernetic control model. Simons (1995) indicates that interactive control particularly plays a part in situations with 'strategic uncertainties'. Although strategic uncertainties are not specifically recognised by Earl and Hopwood (1979), interactive control - which implicitly supposes a functional use for accounting information, i.e. a use to increase economic performance - might be linked to an 'open-minded' learning dialogue role of AIS. However, as Hofstede (1981, p. 198) indicates, with uncertain objectives control will be political control, dependent on power structures and negotiation processes. 'Open-mindedness' might not be a feature then. As probably is also suggested by the more 'cynical' view of Earl and Hopwood (1979) and Burchell et al. (1980), in reality the ammunition 
van Elsacker, ter Bogt \& van Helden

and rationalisation roles of AIS might have some strong links with situations in which Hofstede (1981) would apply a form of political control. The beliefs and boundaries mentioned in Simons' (1995) control model particularly might play a role in situations where political control is applied, in that they might influence the 'mindset' of participants in the organisation.

The Earl and Hopwood (1979) framework, combined with some other elements from control theory, draws attention to various aspects that might play a part in the control of Dutch local government organisations. Probably, elements of the roles of an AIS that are distinguished by Earl and Hopwood (1979) can be found in every organisation, but to a different extent. The framework, combined with the contributions of Hofstede $(1981)$ and Simons $(1990,1995)$ and other authors, is a source of inspiration to find elements to focus on in the empirical research.

\section{Building the Theoretical Framework}

Based on the previously discussed literature, a framework is developed which can give guidance to the empirical case research. For the empirical research, it is necessary to make the various concepts previously presented operational and measurable. In line with the previously discussed theory, the theoretical framework focuses on two main building blocks, i.e. the control context and the roles of $\mathrm{PM}$ in a planning and control cycle. With an eye on the empirical research, each of the two blocks and its main concepts, as well as the way to measure them, will be briefly discussed below.

\section{Control Context and Antecedents}

Two control contexts are distinguished here: a businesslike and a political one. The businesslike context stresses the importance of the formal organisational structure and processes, rules and routines. This context is associated with relatively certain, clear or unambiguous organisational objectives, which is one of the dimensions in the Earl and Hopwood (1979) framework (see also Hofstede, 1981; Birnberg et al., 1983). In this paper, clearly defined organisational objectives are assumed to be achieved by a comprehensive and coordinated set of goals, objectives and targets at various levels of the organisation, or by sets of integrated performance indicators throughout the organisational hierarchy. Budget systems are considered to be important control systems at managerial levels, and are part of the formal control structures and processes (Merchant and Van der Stede, 2003). Therefore, budget tightness is also used as an element of a businesslike control context.

The political context stresses the importance of the gain for organisational legitimacy, and addresses the organisation and its confrontation with internal and external institutions (Hofstede, 1981; Meyer and Rowan, 1977; see also van Helden and Johnsen, 2002, pp. 81-83). This perspective attaches meaning to the budgeting process beyond the formal role of coordination and control (Covaleski, Evans, Luft and Shields, 2003). The presence of a political control context can be 
identified by focusing on possible conflicting pressures on organisational objectives by groups of people, or the possible results of conflicting pressures such as uncertain or ambiguous objectives. This paper primarily focuses on uncertainty and ambiguity of objectives.

Task uncertainty, or uncertainty over the consequences of actions, is the second dimension (see Earl and Hopwood, 1979; Ouchi, 1979; see also Chapman, 1997, p. 201). Task uncertainty relates to both the businesslike and political control context. Task uncertainty can be measured in various ways. In this paper, the level of routine of tasks is considered an indication of task uncertainty (see Perrow, 1970; Abernethy and Brownell, 1997, pp. 234-237). Routineness is supposed to be defined by two dimensions: well-established or analysable techniques for task execution and the degree of variety in tasks encountered. The routineness of tasks is high when they are highly analysable and the number of exceptions is low (Perrow, 1970).

As was indicated before, the level of clearness, uncertainty or ambiguity of objectives is supposed to be a determinant of a businesslike or political context. Measuring ambiguity of objectives is an area that is not well covered within management accounting literature. Indications of the level of ambiguity of objectives can be obtained by measuring possible conflicts of interest between relevant groups of persons (Hofstede, 1981). Oliver's (1991, p. 162) notion of multiplicity, as 'the degree of multiple, conflicting, constituent expectations exerted on an organization' is used to capture the likeliness of ambiguous objectives.

It seems that limited accounting research has been published on the integration of PM in governmental organisations. Two different concepts of integration are suggested in this paper, i.e. between financial and non-financial PM and between lower and higher hierarchical levels in the organisation (see also Brignall and Modell, 2000).

In this paper, tightness of budgetary control is measured by four factors suggested by Van der Stede (2001, p. 134): tolerance of interim budget deviation, detailed line-item follow-ups, intense discussions of budget results and strong emphasis on meeting short-run budget targets.

As the empirical research was conducted in a qualitative, case-based setting, the instruments to measure integration, tightness, routineness, and uncertainty and ambiguity of objectives had to be used in a qualitative way.

\section{Roles of PM}

The roles of PM may vary according to its antecedents (context of control and uncertainty of tasks). Four archetypical roles of PM can be briefly characterised by highlighting the key issues:

The diagnostic role:

- the main role of PM is to diagnose (compare actual and budgeted performance, use of variance information) 
van Elsacker, ter Bogt \& van Helden

- relates to a businesslike context of management control

- relates to relatively high levels of task routine

The learning role:

- the main role of PM is to learn and to change ways of doing, and to unequivocally signal what is important (additional information is important: actual, budget and variance information is used as a reference)

- relates to a businesslike context of management control

- relates to relatively low levels of task routine

The influencing and bargaining role:

- the main role of PM is signalling what is important (focus on key issues) and influencing future budget increases (influencing decision-makers to obtain future budgets; no clarity on importance of actual, variance or additional information)

- relates to a political context of management control

- relates to relatively high levels of task routine

The legitimising role:

- the main role of PM is to report on past performances for reasons of justification (use of historical budget information on achieved performances; no clarity on importance of actual, variance or additional information)

- relates to a political context of management control

- relates to relatively low levels of task routine

Table 1 presents the archetypical roles of PM developed in this section.

To conclude, it seems that theory on accounting information systems and management control as it has developed during the last few decades offers various clues for empirical research in a local government organisation, even though much of this theory originally focused on organisations in the for-profit sector. Based on literature, in this section a framework was developed that provides a basis for the PM roles and related antecedents to focus on in the empirical research.

\section{RESEARCH DESIGN AND METHODS}

The theoretical framework can be seen as a fairly open framework of some specific and some generally defined theoretical concepts. The suggestion that different control contexts can influence the roles of PM is used as a starting point. However, although by now these ideas have some history, it seems that little empirical research was conducted into the relationship between the control context and the applied roles. Consequently, this study is concerned with an exploration of 
Role Variations of Performance Measurement in Dutch Local Government

TABLE I: POSITIONING OF THE ARCHETYPICAL ROLES OF PERFORMANCE MEASURES

\begin{tabular}{lccc}
\hline & \multicolumn{2}{c}{ Control Context } \\
\cline { 2 - 4 } & & Businesslike & Political \\
\hline Task uncertainty & Low & $\begin{array}{c}\text { 'Diagnostic' role } \\
\text { providing variance information }\end{array}$ & $\begin{array}{c}\text { 'Influencing and bargaining' role } \\
\text { promoting particular interests } \\
\end{array}$ \\
& High & $\begin{array}{c}\text { 'Learning' role } \\
\text { assisting decision making }\end{array}$ & 'Legitimising' role \\
& & providing retroactive understanding \\
\hline
\end{tabular}

practices, and if necessary refining of existing theory, and not with a quantitative analysis and testing of hypotheses. This study focuses on the control relationship between politicians and top professional managers, as well as the next lower organisational level.

Given the focus on exploration, case study research seems to be the preferred research method (Berry and Otley, 2004, pp. 235, 242-245; see also Chapman, 1997, p. 203). As the cases are intended to produce theoretical replications and contrasting results four cases with contrasting values of the contextual variables are selected (see Yin, 1989, pp. 52-54).

The first step in the selection process is to search for (groups of) organisational activities for which the roles of PM are expected to vary strongly. For this purpose, interviews were held with eleven city managers (the top professional manager in a municipality) from various larger Dutch municipalities (circa 100,000 inhabitants or more). The main purpose of the interviews was to identify groups of activities that are assumed to relate to different levels of task uncertainty and different control contexts (businesslike or political). The interviews were also used to identify alternative suggestions and insights that could be relevant for the case research later on.

To recognise the more political perspective of control, ambiguity of objectives was used as a key selection criterion, by recording the conflicts regarding organisational objectives. The city managers were asked to indicate a number of functions, in the sense of a group of related activities, which they considered to be under very high and very low conflicting pressures of stakeholders. Interviewees indicated that the levels of conflict of functions, or parts of functions, differed significantly in their organisations. Discussing multiplicity, and the associated level of dispute, it appeared to be easier to indicate functions with high levels than with low levels of dispute.

In general, the city managers were of the opinion that task uncertainty varied less than multiplicity of objectives. They perceived little difference in the level of task uncertainty between different functions. The routineness of almost all organisational functions was regarded as relatively high.

Choosing a case for the combination 'businesslike context and low task uncertainty' and 'political context and high task uncertainty' appeared to be quite straightforward. The interviews pointed to sewerage and spatial planning as 
van Elsacker, ter Bogt \& van Helden

TABLE 2: SELECTED POLICY FIELDS FOR THE CASE RESEARCH

\begin{tabular}{lccc}
\hline & \multicolumn{2}{c}{ Control Context } \\
\cline { 3 - 4 } & & Businesslike & Political \\
\hline Task uncertainty & Low & Sewerage & Welfare payments \\
& High & Economic policy & Spatial planning \\
\hline
\end{tabular}

reasonably clear examples of these two positions, respectively. But the interviews were far less straightforward for the other diagonal of the framework. Welfare payment was eventually selected as a function that relates to a 'political context and low task uncertainty', and economic policy was selected as an example of a function that is related to a 'businesslike context and high task uncertainty'. Table 2 summarises the four selected policy fields.

The second step in the selection process is the selection of organisation(s) to conduct empirical research. Because the case study approach is relying on observations in a small number of cases, the selection of cases within one organisation could be preferable. This could eliminate a number of organisational factors that could otherwise influence the case findings.

The validity of research is improved by including relevant control factors in the selection process. Contingency literature on management accounting indicates that, amongst other things, environment, technology, size, structure and strategy are relevant factors that can influence the design and use of the management control system (see, for example, Chenhall, 2003). The use of the concepts ambiguity of objectives and task uncertainty means that both environment and technology are explicitly integrated in the theoretical framework.

Organisational size is another important factor. This study analyses the use of formal controls in a hierarchical setting; consequently, the selected organisation should not be small. The embedded level of analysis imposes another restriction on organisational size. The hierarchical levels must be directly related, and preferably be able to capture possible conflicts in values or interests. Consequently, the organisational size ought to facilitate an embedded level of analysis between top management and professionals. This excludes very large organisations with multiple management levels. The selected organisation should, at least potentially, also provide the variety of organisational functions which are the subject of this study. The conclusion was that the preferred organisational size would be a municipality with around 100,000 inhabitants or more.

Accounting systems are often seen as being related to organisational structure and centralised or decentralised decision making (see, for example, Chapman, 1997, pp. 193-195). This study is using an instrumental way to measure decentralisation, and uses the existence of departments at an operational level as an indication of a decentralised organisational structure.

On the basis of the selection criteria mentioned above, the municipality of Leeuwarden was chosen as a suitable organisation within which to conduct the 
empirical research. The city is situated in the northern part of the Netherlands, and is the capital of the province of Fryslân.

Each of the four case studies in Leeuwarden is based on about five interviews with politicians and official managers at various organisational levels. Besides this, a lot of evidence was collected from the planning and control documents of the budget years 2004 and 2005. The interviews were summarised in a report, on which the interviewees were asked to comment. The definitive report was used as a basis for the research. For each case researched a report was written which was discussed with some participants in the organisation.

\section{FINDINGS FROM THE CASE RESEARCH}

\section{Different Types of Analysis}

As was indicated above, our theoretical framework is inspired by an admittedly simplistic but suggestive framework by Earl and Hopwood (1979; Burchell et al., 1980, p. 15). However, to find out to what extent their suggestions could be of help to explain reality, our analysis started with a straightforward application of our theoretical framework. This means that the focus is first on the question of whether different values of the contextual variables (i.e. the antecedents) give rise to the assumed roles of PM. As will be shown below, the results of this analysis indicated that the theoretical framework could explain PM roles in the cases only to a limited extent. Therefore, the cases were analysed further, in order to provide a better understanding of PM roles in varying circumstances. The latter analysis has informed the redesign of the theoretical framework presented in the next section.

\section{Findings Based on the Theoretical Framework}

Table 3 provides an overview of the assumed and observed roles in each of the four case studies. Each of the four cases was selected because of its presumed extreme position in the theoretical framework, pointing to a specific archetypical role of PM. However, reality was less clear than was supposed on the basis of the interviews with the city managers, and the empirical research showed that the values of the contextual variables were less extreme than expected. This also induced a more diffuse picture of the assumed PM roles, as a comparison of the first and second row for each case in Table 3 reveals. The research also gave evidence about the observed roles, i.e. the role of PM in practice. As can be seen from Table 3, in the cases the assumed roles are often partly and sometimes only limitedly observed or even absent (see the second and third rows for each case). Moreover, occasionally roles are observed in situations where they were not assumed. These findings suggest that the relationships between a particular position in the theoretical framework and the various roles of PM are far less straightforward than originally thought.

Not only are the positions of the cases in the framework less extreme than expected (compare the archetypical and assumed roles), the empirical research also 
van Elsacker, ter Bogt \& van Helden

TABLE 3: DIFFERENCES IN ARCHETYPICAL, ASSUMED AND OBSERVED ROLES OF PM IN THE CASES

\begin{tabular}{|c|c|c|c|c|c|c|c|}
\hline \multirow[b]{2}{*}{$\begin{array}{l}\text { Case } \\
\text { study }\end{array}$} & \multicolumn{2}{|c|}{ Contextual variables } & \multirow{2}{*}{$\begin{array}{l}\text { Archetypical, } \\
\text { assumed or } \\
\text { observed } \\
\text { roles }\end{array}$} & \multicolumn{4}{|c|}{ Types of roles } \\
\hline & Context & $\begin{array}{c}\text { Task } \\
\text { uncertainty }\end{array}$ & & Diagnostic & Learning & $\begin{array}{l}\text { Influencing } \\
\text { and } \\
\text { bargaining }\end{array}$ & Legitimising \\
\hline \multirow{3}{*}{ Sewerage } & \multirow[t]{3}{*}{ Businesslike } & \multirow[t]{3}{*}{ Low } & Archetypical & & & & \\
\hline & & & Assumed & & & & \\
\hline & & & Observed & Partly & & & Partly \\
\hline \multirow{3}{*}{$\begin{array}{l}\text { Economic } \\
\text { Policy }\end{array}$} & \multirow[t]{3}{*}{ Businesslike } & \multirow[t]{3}{*}{ High } & Archetypical & & & & \\
\hline & & & Assumed & & & & \\
\hline & & & Observed & Limited & Partly & Limited & Present \\
\hline \multirow{3}{*}{$\begin{array}{l}\text { Welfare } \\
\text { Payment }\end{array}$} & \multirow[t]{3}{*}{ Political } & \multirow[t]{3}{*}{ Low } & Archetypical & & & & \\
\hline & & & Assumed & & & & \\
\hline & & & Observed & Partly & Present & Present & Present \\
\hline \multirow{3}{*}{$\begin{array}{l}\text { Spatial } \\
\text { Planning }\end{array}$} & \multirow[t]{3}{*}{ Political } & \multirow[t]{3}{*}{ High } & Archetypical & & & & \\
\hline & & & Assumed & & & & \\
\hline & & & Observed & Partly & Limited & Present & Present \\
\hline
\end{tabular}

suggests that in practice the various roles of PM are not exclusively related to specific contextual situations according to this framework (compare the assumed and observed roles). For that reason we investigated whether a more sophisticated framework could take this analysis further. In the following subsections the case study findings are analysed in more detail to explain the roles of PM-use in Dutch municipalities. This will ultimately result in a more appropriate framework.

\section{Further Analysis of the Four Cases}

Each of the four case studies will be analysed now, using both constructs from the theoretical framework and important insights arising from each of the case studies. 
Thereafter, some pointers for an adapted framework will be provided. In this analysis a fifth role is added to the aforementioned four roles of PM, which combines aspects of the learning and influencing/bargaining role. This additional role is expected to signal what is important to the user of information.

\section{Welfare Payment Case}

The activities of welfare payment are to provide financial support to people who cannot support themselves. Municipal welfare payments are largely paid for by central government but, for example, the municipality has to take care of the costs of unforeseen increases in the number of citizens entitled to welfare payment, which is a considerable financial risk.

Although the objectives of this policy field are clear, various stakeholders are committed to their own objectives: central government to reducing the number of clients dependent upon welfare payment, the city council on providing opportunities for temporary jobs for people having no regular job, and the professional managers to guaranteeing that relevant processes will function adequately. Furthermore, welfare payment is characterised by standardised activities. Although the expectation was that this case would relate to a political context, it thus combines characteristics of a political and a businesslike context. The context is political because of conflicting objectives, but it is businesslike because the policy field is characterised by undisputable objectives.

The fact that the organisation is faced with high political risks (in a financial sense and related to the proper execution of law) seems to be crucial to the use of PM. The work load of the division is highly dependent on developments in unemployment, which are not controllable by the municipality. This explains why variances between budgeted and actual levels of welfare payments are not really important, while it is crucial to monitor actual developments of the number of clients asking for a welfare payment, because these determine the actual workload of the division. Moreover, inadequate monitoring of this workload is a source of risk for the city (e.g. financially, or because of increased risks of misapplication of the rules).

There is both financial and non-financial information in budgets and reports at all levels of the hierarchy, e.g. the political level, the division level and the level of operational management. Experiences with the five roles of PM can be summarised as follows. The diagnostic role (e.g. variance analysis) seems to be constrained to aggregated financial information for the top of the organisation, which has a certain interest in remaining within budgetary limits. Variance analysis of non-financial information is mainly applied at lower levels of the hierarchy. The learning role is of importance because non-financial information is used to discuss changes in working methods or policies. The signalling role, which highlights both financial and non-financial aspects, is even more important. The influencing role, in which information about changing circumstances is used to underline budget changes (especially increases in the budget), is crucial. Finally, the reporting role, which explains past performance, is also clearly apparent. 
van Elsacker, ter Bogt \& van Helden

When the number of clients is known, tasks to be performed are quite clear, which indicates a businesslike context at the operational level. At this level, concrete aspects of the activities of the division, such as taking decisions on applications for a welfare payment in time, the extent of welfare fraud and the number of debtors, can be controlled, as corresponding PMs are. These items, therefore, play a role in the planning and control at the operational level.

Generally speaking, control is rather tight, both at the political and the operational level.

\section{Sewerage Case}

The activities of the sewerage division are to develop and maintain a sewer system in the municipality that transports wastewater and rainwater out of the city (where it can be treated by a water board and discharged into canals and lakes). The objectives of sewerage are clear, although the political level focuses on issues (giving attention to complaints about sewerage works) other than those of the operational level (which is interested in such issues as progress in the execution of sewerage projects). However, in general, the context is regarded as businesslike. Although activities are characterised as routine, the execution of sewerage works (new investments or maintenance works) is uncertain to a fairly high extent. This is due to the fact that the execution of sewerage works is only controllable to a limited degree by the sewerage division and highly dependent upon decisions made outside the sewerage division, e.g. by the spatial planning and roads works department (which takes a high interest in the prevention of traffic problems).

At the political level, control is very distant, a point which can be observed from the fact that only once every four years, when plans are made, is there political involvement to some extent. This distant form of control by the political level is mainly caused by a lack of political interest in this policy field, which is reinforced by the absence of financial or non-financial problems and organisational risks during the last decade. For this reason, at the political level neither financial nor non-financial PMs seem to play an important role. At the operational level, operational performances are important, especially those related to projects being completed in time. However, financial aspects seem to play a rather peculiar role at that level, in the sense that it is more important to avoid underspending (due to delays in projects) than to avoid overspending of budgets.

The budget roles can be characterised more particularly. The diagnostic role is only important at the operational level in order to scrutinise the progress of the sewerage projects. Control aspects are time (completion of projects within the agreed time frame) and required project quality. The diagnostic role of financial information is developed to a limited extent because of a lack of financial stress and little interest at the political level. The learning and signalling roles of budgets are largely absent. The influencing role and legitimising roles are present but not important, due to the fact that the sewerage planning cycle is based on a multi-year time frame and because financial issues are not very constraining. 
Role Variations of Performance Measurement in Dutch Local Government

Controls at the political level are in general loose, whereas at the operational level controls of sewerage projects are rather tight.

\section{Economic Policy Case}

Economic policy performs several activities, mainly in the sphere of promotion, communication and coordination, which are intended to stimulate the economy and employment in the municipality. The objectives of economic policy are clear and undisputable, and particularly directed to achieving employment opportunities for the city. Consequently, this policy field is characterised as businesslike. Moreover, politicians show a high interest in and a strong commitment to this policy field. Economic policy is characterised by both routine activities (such as business visits and external communication) and non-routine activities, especially projects, some of which are difficult to foresee. Each of these projects is controlled by tailor-made plans and reports, while standardised cyclical controls are of minor importance.

Three factors explain why, unlike undisputable objectives and a strong political interest, PM does not play a key role. First, the relationship between objectives and actions is highly diffuse (due to internal uncertainty), i.e. the objectives do not give directives for actions. This is reinforced by the second factor: external influences, such as investment initiatives from companies, strongly determine outcomes of the economic policy field. In other words, external uncertainty leads to high uncontrollability. Third, economic policy is highly interdependent upon actions taken in other policy fields, such as infrastructure and housing.

The diagnostic role is apparent, but especially related to financial aspects at an aggregated level and to non-financial aspects at lower levels in the organisation. Both the signalling and learning role have some importance. Learning seems to be restricted to specific actions to be undertaken and not to discuss various ways to achieve certain policy goals. The influencing role is apparent, not only in reference to the future budget of the organisation, but also in influencing decision making in other related policy fields. The legitimising role, which informs on the progress of projects, is also applied.

Finally, controls, both financial and non-financial and at various organisational layers, are loose.

\section{Spatial Planning Case}

Spatial planning covers a wide area of activities in the field of supporting and planning civil developments, such as planning and development of zones and working out strategic visions on development. Politicians regard spatial planning as important and municipal politicians often participate in operational decision making. Some objectives are clear, but most of the objectives are stated in more general terms. These objectives appear to be purposely ambiguous, because this gives room for executional flexibility. Ambiguity does not seem to be a response 
van Elsacker, ter Bogt \& van Helden

to conflicting institutional pressures, but more a strategic choice. Consequently, the context combines aspects of a political context (ambiguous objectives) and a businesslike context (undisputable objectives). Spatial planning occasionally concerns routine tasks (like keeping regulation and zone planning up to date), but it more particularly concerns non-routine activities, e.g. spatial planning projects.

Next to financial targets, this policy field is characterised by rather vague, mainly process-related goals, such as having up-to date plans. At a high organisational level variance analysis plays a role, but with much room for interpretation, caused by complexity and uncontrollability. At a lower level, performance targets are concrete in terms of specific plans or activities. Then the diagnostic role of budgets is apparent from progress reports of the various projects. The learning and signalling roles of budgets are unimportant, but budgetary information is used to influence future budgets. The legitimising role, which explains to what extent projects are realised, is also of importance. Because organisational objectives and performances are seldom integrated with operational tasks, operational project control is loosely coupled with organisational objectives.

Financial and non-financial organisational control is characterised as rather loose.

\section{SUMMARISED CASE FINDINGS AND A REDESIGN OF THE THEORETICAL FRAMEWORK}

It seems that the importance attached to PM is primarily determined by the extent to which a policy field could be regarded as politically sensitive. Political sensitivity indicates that the political level considers regular attention to be required because politicians are interested in a policy field, want to consider possible interventions and/or foresee that they will be held accountable. An examination of the cases suggests that only sewerage could be perceived as highly politically insensitive. This implies that politicians confine themselves to distant control - looking at long-term developments - and leaving the yearly planning and control cycle mainly to managerial levels of the policy fields. Only when distortions occur - such as the need for a strong tariff increase, or serious complaints about the functioning of the sewerage system - the political level might consider being more closely involved, probably temporarily, in planning and control.

The research indicates that the other three policy fields are characterised by a relatively strong degree of political interest. However, only in the welfare payment case does this lead to a relatively strong tightness of the controls. The reason for this seems to be that, unlike the two other policy fields with a high political attention, welfare payment is faced with severe political risks (because of financial risks and misapplication of law and, for example, when clients have to wait too long for payments or when too little clients enter the regular labour market). Because of these risks, politicians and managers want to monitor a number of relevant performance indicators. It also means that many roles of PM are pronounced in this case. 
The two other cases, economic policy and spatial planning, reveal a rather limited use of PM. Although the political level shows an interest in these policy fields, businesslike controls seem to be inappropriate, except for financial indicators at an aggregated level. For this, two reasons seem to arise out of both cases.

First, in both cases non-routine activities, particularly projects, are relevant. This implies that it is difficult to aggregate non-financial information. This leads on the one hand to financial controls at the highest level (where financial resources of different projects can be compensated), whereas on the other hand non-financial information is decoupled between organisational layers.

The second reason relates to the fact that the relationship between objectives and actions is problematic (internal uncertainty), and/or influences of external factors are strong (external uncertainty). In these circumstances, non-financial controls are problematic. This reason suggests that diagnostic controls are of relatively low importance. At lower levels in the organisation improvisation and adaptability are important. PM is mainly used for legitimating previous actions and for supporting future budgets. Moreover, when PM is used controls are sometimes loose and in other cases tight.

Finally, we observe that many roles of PM apparently exist, irrespective of the value of both contingency variables, i.e. context and task uncertainty, in particular diagnostic financial control, influencing future budgets and progress reporting. As has been argued above, other PM roles, especially signalling and learning, only emerge in relationship with specific contextual circumstances when policy fields are of a high political interest or are faced with substantial political risks.

\section{An Adjusted Framework}

Based on theory, case findings and the considerations indicated above, Figure 1 suggests an adjusted framework. On the one hand, this framework is based on ideas drawn from Earl and Hopwood (1979), Hofstede (1981), Simons (1990, 1995), and Merchant and Van der Stede (2003). However, the empirical research indicates that the contributions of these authors do not suffice to properly explain practices observed in the cases. For that reason, the framework is also based on an interpretation of the case findings. The political sensitivity aspect, in particular, is not included in the framework and contingency literature discussed in this paper. However, the cases researched suggest that in practice political sensitivity is a very important aspect that influences the control forms applied and the roles of PM in local government organisations. This probably can be explained from the fact that politicians - and citizens, who are the voters in elections - are not only, or primarily, interested in control that is functional and efficient in an economic sense, but also in control that is functional and efficient in a political sense (see ter Bogt, 2003, p. 155, 2008, pp. 37-39).

The adjusted framework in Figure 1 indicates that when the activities in a certain policy field are not politically risky (e.g. are not related to significant financial deficits, operational malfunction or the possibility of being held accountable for 
van Elsacker, ter Bogt \& van Helden

underperformance) and do not offer political opportunities (e.g. are not able to offer politicians the possibility of fulfilling their political ambitions), the policy field is seen politically as insensitive and control of performances will be loose. In that case, the applied roles of PM are restricted to 'standard' roles, some of which are not very pronounced, with some attention applied to such aspects as reporting. However, in general this 'standard' role also means that there is a considerable amount of attention for financial diagnostic control (or financial diagnostic control at the top level of the organisation and diagnostic operational control at the lower level).

When there are few political risks connected with a certain policy field, but politicians observe political opportunities with certain activities within this field, then there might be an interest in some specific objectives and performances and the activities can be labelled politically sensitive. The extent to which they are sensitive, and whether control will be loose or tight, seems to depend on the situation. When there is not a 'learning-to-do' attitude, the prime role of PM might be a signalling one (which, however, in practice will be combined with such standard roles as influencing budgets and progress reporting: indicated by the dotted line in Figure 1). However, when a learning-to-do attitude does exist, the prime role of PM might be the learning one (this role, again, is

FIGURE I: ADJUSTED FRAMEWORK

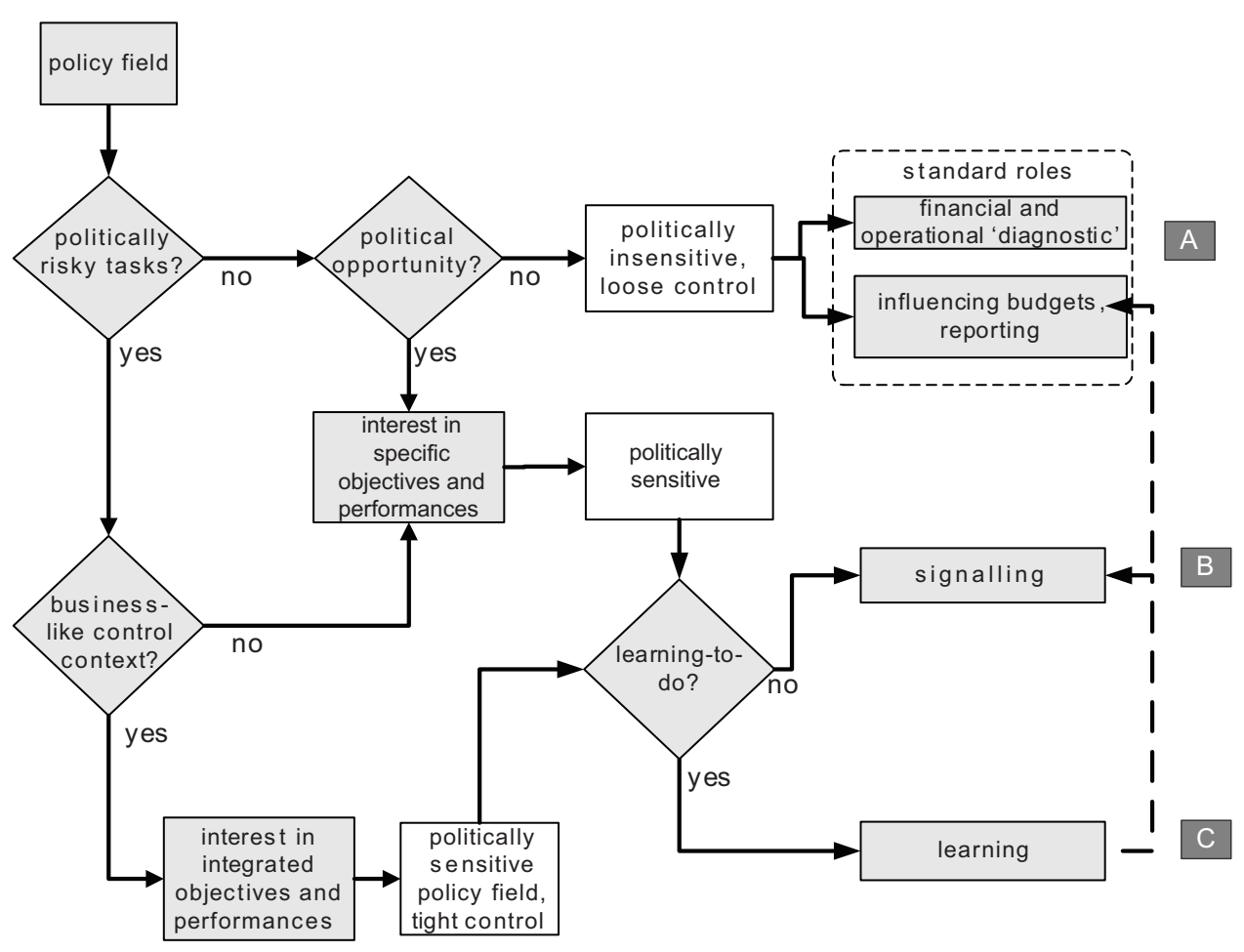


combined to some extent with a signalling role and the 'standard roles', such as progress reporting; see the dotted lines). When a policy field is regarded as politically risky and there is a businesslike control context (unambiguous organisational objectives and an integration of organisational and operational performance indicators) then an interest in integrated objectives and performances could be expected. The activities are politically sensitive and performances are controlled tightly.

The four cases studied can be positioned in Figure 1.

When there is no political interest and the policy field is not faced with political risks, PM roles are not pronounced. Variance analysis of financial issues at the top of the organisation is clearly apparent, as is variance analysis at lower levels of the organisation of operational (non-financial) aspects. However, the influencing and legitimising roles of PM are of minor importance, while the signalling and learning roles are completely absent. This pattern of PM roles applies to the sewerage case (see position A in Figure 1).

When there is a political interest in a certain policy field, almost all standard PM roles are applied. This regards the diagnostic role, the influencing role and the legitimising role. Often PM roles are more focused on financial issues at the top of the organisation, whereas at lower levels of the organisation relatively more attention is paid to operational issues, in the form of project control. The signalling and learning roles are also important. However, the learning role especially does not seem to be very pronounced, because it is restricted to assessing current working methods rather than discussing alternative practices to align them to the goals of the organisation. This pattern of PM roles could apply to both the economic policy and spatial planning cases (see position B in Figure 1).

Finally, next to being of political interest, a policy field may also face particular risks, such as a financial risk of achieving a deficit position or an operational risk of not meeting mandatory performance standards coming from central government. Then PM roles are similar to those indicated above for the economic policy and spatial planning cases, with one exception. Now the learning role is also more pronounced. The organisation is faced with pressures to continuously reassess its working methods related to the goals to be achieved. This pattern of PM roles seems to apply to the welfare payment case (see position $\mathrm{C}$ in Figure 1).

In the situations indicated at B and C in Figure 1, the standard roles also are of more importance than in situation A.

\section{CONCLUSIONS AND REFLECTION}

The research of four cases (policy fields) in the municipality of Leeuwarden showed that a theoretical framework based on the control context and uncertainty of tasks could hardly explain the observed roles of PM. It turned out that in reality the cases did not fit each of the four archetypes that were distinguished. Probably in practice policy fields often do not only take one extreme position, as 
van Elsacker, ter Bogt \& van Helden

is suggested by the theoretical framework. Moreover, PM roles in each of the four 'archetypical' cases were less straightforward than was suggested by the theoretical framework. In practice, various roles played a part to some extent. Besides this, the cases indicate that perceived political risks and interests play an important role in the control of a policy field and the role of accounting information. To some extent, ideas drawn from Ouchi (1979), Hofstede (1981), Earl and Hopwood (1979), Simons (1990) and Van der Stede (2001) are helpful in understanding the case findings. However, they could explain the four cases only to a limited extent. For that reason, an adjusted framework was developed in this paper, in which political sensitivity (related to political opportunity and risks) also plays an important role.

This study contributes in various ways to the existing body of knowledge on management control of governmental organisations. First, it has explored the distinction between political and businesslike control in a multidimensional sense. Four dimensions are at stake, i.e. the extent to which organisational objectives are clear and those objectives are undisputable, the degree of integration of performance measures (in the hierarchy and between financial and non-financial aspects), and control tightness. Second, roles of PM are explored by unbundling them into various sub-roles. Those recognised sub-roles are diagnostic financial and nonfinancial control, influencing future budgets, reporting, signalling and learning. Third, in the adjusted framework only two sub-roles are related to certain contextual circumstances, especially signalling and learning, whereas the other sub-roles apparently are largely unrelated to those circumstances. Finally, the research highlights the importance of political interest and political risks as antecedents of PM roles in the four cases.

Our field study in the public sector seems to supplement existing management control theory. Seminal contributions to theory in this field, which inspired our original theoretical framework, indicate that cybernetic forms of control are associated with contextual circumstances of clear and undisputable objectives, task certainty and measurable outputs. A cybernetic control form is characterised by setting targets, followed by monitoring actuals and analysis of variances between targets and actuals, and finally by considering corrective actions. One of our case studies, sewerage, seems to be an example of the contextual circumstances in which a cybernetic control form could be expected. This case, however, reveals an absence of control at the top level of the organisation, whereas the assumed way of control is only observed to some extent at lower levels in the hierarchy. In this case, absence of control at the top level of the organisation is primarily explained by low levels of political sensitivity.

This research viewed performance measurement mainly from a functional and rather narrow control perspective, particularly by examining the roles of PM in the planning and control cycle, in which local government politicians and top managers are the main actors. However, this perspective may insufficiently recognise other factors and influences and other types of actors, especially citizens, consumers of services and oversight bodies, who also have substantial 
Role Variations of Performance Measurement in Dutch Local Government

interests in good performing governmental organisations (Chenhall, 2003, p. 131; Pollitt, 1988, 2006). This could imply that a broader view on PM systems is more likely to emphasise elements of equity, service quality and broader societal effects.

\section{REFERENCES}

Abernethy, M.A. and Brownell, P. (1997). Management Control Systems in Research and Development Organizations: The Role of Accounting, Accounting, Organizations and Society, Vol. 22, Nos. 3-4, pp. 233-248.

Anthony, R.N. (1988). The Management Control Function, Boston, MA: Harvard Business School Press.

Behn, R.D. (2003). Why Measure Performance? Different Purposes Require Different Measures, Public Administration Review, Vol. 63, No. 5, pp. 588-606.

Berry, A.J. and Otley, D.T. (2004). Case-Based Research in Accounting, in C. Humphrey and B. Lee (eds), The Real Life Guide to Accounting Research: A Behind-the-Scenes View on Using Qualitative Research Methods, Amsterdam: Elsevier.

Birnberg, J.G. (1998). Some Reflections on the Evolution of Organizational Control, Behavioral Research in Accounting, Vol. 10, Supplement, pp. 27-46.

Birnberg, J.G., Turopolec, L. and Young, S.M. (1983). The Organizational Context of Accounting, Accounting, Organizations and Society, Vol. 8, Nos. 2-3, pp. 111-129.

Bogt, H.J. ter (2003). A Transaction Cost Approach to the Autonomization of Government Organizations: A Political Transaction Cost Framework Confronted with Six Cases of Autonomization in the Netherlands, European Journal of Law and Economics, Vol. 16, No. 2, pp. 149-186.

Bogt, H.J. ter (2004). Politicians in Search of Performance Information? Survey Research on Dutch Aldermen's Use of Performance Information, Financial Accountability and Management, Vol. 20, No. 3, pp. 221-252.

Bogt, H.J. ter (2008). Recent and Future Management Changes in Local Government: Continuing Focus on Rationality and Efficiency?, Financial Accountability and Management, Vol. 24, No. 1, pp. 31-57.

Bogt, H.J. ter and Helden, G.J. van (2005). A Reflection on Accounting Reforms in Dutch Government, in J. Guthrie, C. Humphrey, L.R. Jones and O. Olson (eds), International Public Financial Management Reform: Progress, Contradictions, and Challenges, Greenwich: Information Age Publishing.

Bordewijk, P. and Klaassen, H.L. (2000). Wij Laten Ons Niet Kennen, Den Haag: VNG.

Brignall, S. and Modell, S. (2000). An Institutional Perspective on Performance Measurement and Management in the 'New Public Sector', Management Accounting Research, Vol. 11, No. 3, pp. 281-306.

Bruijn, H. de (2002). Managing Performance in the Public Sector, London: Routledge.

Burchell, S., Clubb, C., Hopwood, A., Hughes, J. and Nahapiet, J. (1980). The Roles of Accounting in Organizations and Society, Accounting, Organizations and Society, Vol. 5, No. 1, pp. 5-27.

Chapman, C.S. (1997). Reflections on a Contingent View of Accounting, Accounting, Organizations and Society, Vol. 22, No. 2, pp. 189-205.

Chenhall, R.H. (2003). Management Control Systems Design within its Organizational Context: Findings from Contingency-Based Research and Directions for the Future, Accounting, Organizations and Society, Vol. 28, Nos. 2-3, pp. 127-168. 
van Elsacker, ter Bogt \& van Helden

Covaleski, M.A., Evans III, J.H, Luft, J.L. and Shields, M.D. (2003). Budgeting Research: Three Theoretical Perspectives and Criteria for Selective Integration, Journal of Management Accounting Research, Vol. 15, pp. 3-49.

Donaldson, L. (2001). The Contingency Theory of Organizations, Thousand Oaks, CA: Sage Publications.

Earl, M.J. and Hopwood, A.G. (1979). From Management Information to Information Management, in H.C. Lucas, F.F. Land, T.J. Lincoln and K. Supper (eds), The Information Systems Environment, Amsterdam: North-Holland.

Helden, G.J. van, and Bogt, H.J. ter (2001). The Application of Businesslike Planning and Control in Local Government: A Field Study of Eight Dutch Municipalities, Local Government Studies, Vol. 27, No. 1, pp. 61-86.

Helden, G.J. van, and Johnsen, $\AA$. (2002). A Comparative Analysis of the Development of Performance-Based Management Systems in Dutch and Norwegian Local Government, International Public Management Journal, Vol. 5, No. 1, pp. 75-95.

Hofstede, G. (1981). Management Control of Public and Not-for-Profit Activities, Accounting, Organizations and Society, Vol. 6, No. 3, pp. 193-211.

Hood, C. (1995). The New Public Management in the 1980s: Variations on a Theme, Accounting, Organizations and Society, Vol. 20, Nos. 2-3, pp. 93-109.

Macintosh, N.B. (1994). Management Accounting and Control Systems: An Organizational and Behavioral Approach, Chichester: John Wiley \& Sons Ltd.

Merchant, K.A. and Stede, W.A. Van der (2003). Management Control Systems: Performance Measurement, Evaluation, and Incentives, Harlow: Financial Times/Prentice Hall.

Meyer, J.W. and Rowan, B. (1977). Institutionalized Organizations: Formal Structure as Myth and Ceremony, American Journal of Sociology, Vol. 83, No. 2, pp. 340-363.

Oliver, C. (1991). Strategic Responses to Institutional Processes, Academy of Management Review, Vol. 16, No. 1, pp. 145-179.

Ouchi, W.G. (1979). A Conceptual Framework for Design of Organizational Control Mechanisms, Management Science, Vol. 25, No. 9, pp. 833-848.

Perrow, C. (1970). Organizational Analysis: A Sociological View, London: Tavistock Publications.

Pollitt, C. (1988). Bringing Consumers into Performance Measurement: Concepts, Consequences and Constraints, Policy and Politics, Vol. 16, No. 2, pp. 77-87.

Pollitt, C. (2006). Performance Information for Democracy: The Missing Link?, Evaluation, Vol. 12, No. 1, pp. 38-55.

Simons, R. (1990). The Role of Management Control Systems in Creating Competitive Advantage: New Perspectives, Accounting, Organizations and Society, Vol. 15, Nos. 1-2, pp. 127-143.

Simons, R. (1995). Levers of Control: How Managers Use Innovative Control Systems to Drive Strategic Renewal, Boston, MA: Harvard Business School Press.

Van der Stede, W.A. (2001). Measuring 'Tight Budgetary Control', Management Accounting Research, Vol. 12, No. 1, pp. 119-137.

Yin, R.K. (1989). Case Study Research: Design and Methods, Newbury Park, CA: Sage Publications.

Zimmerman, J.L. (2000). Accounting for Decision Making and Control, Boston, MA: McGrawHill Irwin. 